\title{
LA LENGUA POÉTICA DE EUGENIO G. DE NORA. ACERCA DE LA BIMEMBRACIÓN
}

\author{
M. GARCÍA-PAGE \\ UNED. Facultad de Filología
}

\section{RESUMEN}

Una de las características sintácticas de la poesía de Eugenio G. de Nora, por el elevado grado de recurrencia y la diversidad de formas de expresión, es el fenómeno conocido tradicionalmente como «bimembración» (o isocolon o párison), una manifestación particular de la estructura binaria.

Junto con otros recursos estilísticos y figuras, la bimembración consituye un procedimiento dominante en la lengua literaria del poeta.

Palabras clave: Lenguaje poético, retórica, bimembración, estructura binaria.

\section{THE POETIC LANGUAGE OF EUGENIO DE NORA. ABOUT BI-MEMBRATION}

\section{ABSTRACT}

On the syntactic features of Eugenio de Nora's poetry which stands out on account of both its frequency and the diversity of form it takes is the fenomenon traditionally known as «bimembración» (or isocolon o párison); a distinctive expression of a binary structure.

Along with other stylistic features and tropes, bimembración may be considered a central device in the poet's literary language.

Key Words: Poetic language, rhetoric, bimembracion, binary structure.

1. Uno de los rasgos formales distintivos, si no el más sobresaliente, de la lengua poética de Eugenio de Nora, es la seriación de estructuras o «conjuntos semejantes», mecanismo de orden sintáctico conocido más comúnmente, entre otras denominaciones, como plurimembración ${ }^{1}$, si bien su morfolo-

\footnotetext{
${ }^{1}$ A pesar de ser uno de los formalismos estilísticos más sobresalientes de la lengua poética de Eugenio García de Nora, no ha sido suficientemente tratado en los estudios críticos que se han realizado sobre su poesía o quehacer artístico, tales como García Méndez (2003).

Plurimembración es el término acuñado por D. Alonso, profusamente divulgado en los estudios literarios españoles, si bien alternante a veces con los de simetría bilateral y pluralidades (Alonso 1927, 1944, 1955, esp. 117-173 y 174-221..., ALONSO Y Bousoño 1951, esp. caps. 1,2 y 5), y se corresponde con los más regulares de la tradición retórica clá-

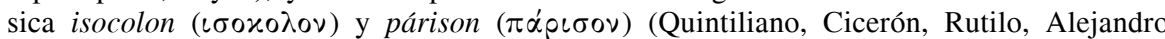
Sofista, Jiménez Patón, etc.; FERNANDo DE HERRERA utiliza el nombre de compar). Véanse, entre otros, LAUSBERG (1960, § 719) y MAYORAL (1994, § 7.2.).
} 
gía más representativa en la obra de Nora es conforme a su expresión más sencilla (también la más recurrente, sin duda, en la lengua artística de todos los periodos literarios): la estructura binaria o geminada o bimembración, que se revela sobremanera prolífica mediante la composición de parejas léxicas o binomios sintagmáticos ${ }^{2}$ :

qué hermoso y triste es comprender (256)

( Cantos encendidos

del poeta!) ¡Árbol

verde y florecido!

Igual que un corazón tibio

que te sabe y te recuerda (256)

Pensemos en una ciudad

entre la noche y la mañana (318)

en mis ojos dominan tus labriegos y reyes; pero por sobre todo, tu futuro es quien vive y crepita y combate en mi sexo y mis sienes (286)

Presumiblemente de forma paralela, sin el conocimiento de la existencia de estos estudios de estilística castellana, el artificio que nos ocupa va a ser objeto de reflexión concienzuda en los años 60 del siglo pasado por autores como LEVIN, S.R. (1962b) y aquellos en los que caló hondo el trabajo programático de JAKOBSON, Roman (1960), presentado al congreso de Bloomington [1958] sobre la «función poética». Como es sabido, Jakobson fundamenta su teoría sobre el lenguaje poético en la repetición; y Levin bautiza dicho mecanismo con el nombre de coupling ('emparejamiento'). Véanse, asimismo, LEVIN (1962a), RUWET (1972, passim, 1974) y LÁZARO CARRETER (1972), entre otros.

${ }^{2}$ Junto con algunas plurimembraciones que se recogen indirectamente en los ejemplos del trabajo, son muestras de la estructura tripartita textos como los siguientes, compuestos por miembros formalmente simétricos (los tres últimos, además, imprimen un carácter cerrado al verso al celebrarse una esticomitia perfecta):

Sin ventanas, va la noche apretando la atención contra sus pechos, mientras miro, mientras callo, mientras quedo (184)

¡Oh eternidad! Ella aquí:

Verla, nacerla, mirarla...

Me aparecen siempre con uniformes vestidos por dentro, universales, repetidos, unos (290) [...]

Sólo nosotros, hombres, con palabras distendemos, descoyuntamos, cercenamos seres de seres, seres (356) 
El carácter persistente con que se manifiesta en la entera trayectoria artística del poeta (el artificio menudea en las composiciones más tempranas, Amor prometido y Cantos al destino, y en absoluto se extingue en los últimos libros, España, pasión de vida) y el elevado índice de repetición o recurrencia con que, incluso machaconamente, aparece en algunas creaciones líricas (como «Primer poema de amor», de la sección «Cantos» de Cantos al destino ${ }^{3} ;$ «Paciencia» y «Canto», de España, pasión de vida; o el texto

${ }^{3}$ Por las limitaciones espaciales, sólo reproducimos íntegramente, a modo de ejemplo, este poema, de la primera etapa, y, a continuación, dos fragmentos estróficos de algunas de sus últimas poesías («Hiroshima», de No he de callar..., y «El viajero (IV)», de la sección «El devenir», de Angulares). Las series plurimembres son, en su mayoría, manifestaciones de la estructuración binaria, la más representativa (el número que aparece entre paréntesis se refiere a la página de donde es extraído el ejemplo, según la edición de Santos Alonso de la selección poética de Eugenio de Nora Días y sueños. Obra poética resumida (1939-1992). Madrid, Cátedra),

Después de tanto amor rosa del sueño, de tanta fe y nostalgia incompartida, he aquí por fin con voluntad y dueño, cómo el amor encarna y nace a vida.

Erguido árbol hermoso,

o esbelta luz yacente, como en un bosque umbroso la belleza tendida de una fuente, en dos pechos se ve manar, dichoso, y cuerpo abajo fluir, esbeltamente.

¡En él la tierra más ansiada, el agua más vivaz y rumorosa, él es aura ceñida, enamorada, $y$ es fuego, amor que se resuelve en nada: el fuego, imagen de la vida hermosa!

Es la mar agitada y conmovida que alza dagas y ciñe sus cadenas, y no sé si el afán lo abre su herida, o quizá irrumpe de mis propias venas.

Pero está aquí. Yo soy el señalado por un dios implacable y violento, a este cielo ascendido, y destinado a fundar una sangre sobre el viento.

Sé que tan sólo para amar se nace; me arrebató, me lleva tal destino.

Así es como la sangre inunda y hace más ancho el río que de los siglos vino.

Las vidas de mil muertos siento oscuras, y mil aún no nacidos claman, quieren vivir, amar.
No un sueño; mil futuras primaveras florecen en mis venas; un mar de olas de vida que no mueren, que avanzan, que refluyen, que interfieren y que se alzan cada vez más plenas.

Por eso me doy todo con labios y con brazos, y derramo caricias, oh belleza ofrecida, más que por tu apariencia fugaz, por esos lazos, que a la muerte me atan, y llevan a la vida.

Los pechos encendidos, y los labios deshechos, y este oro derramado que brilla como el día, aquí junto a mis ojos prometen otros pechos cabelleras y bocas y cantos de alegría.

Si te deshago a besos, si me hundo en tu vacío, ¡oh carne del placer, ligera y venturosa!, mientras en uno ceden este cuerpo y el mío, algo sacro nos mece, como el aire a una rosa.

Como rosa en el aire penetrada, el desnudo es plenitud gozosa, cumplida y verdadera. Así un cuerpo en reposo, abandonado y mudo es cántico y misterio como la primavera.

Mira el cielo maduro de promesas y estrellas, cómo eleva el silencio con el amor la vida, y enlazando almas, cuerpos, constelaciones bellas, nos devuelve a esta isla de beatitud perdida.

Ser hombre, y conocerlo. Cumplir ese destino mientras el cielo calla y el mundo esbelto gira. Algo, que no sabemos, nos alza a lo divino; y así un pájaro canta y enmudece la lira. (115-117) 
de la sección «Otra voz», del citado libro Cantos al destino, que comienza con el verso «Durante tiempo y tiempo») permiten aventurar que la bimembración o plurimembración es un rasgo de «estilo» de la poesía de Eugenio de Nora: si, por un lado, cabría afirmar que son pocos o más bien raros los poemas confeccionados sin hacer uso de alguna suerte de apareamiento formal, siguiendo uno de los cauces expresivos de la figura acumulación (congeries, sinatroísmo), también son, por otro lado, asaz numerosos los que se componen de estrofas tejidas con hiladas de parejas léxicas o sintagmáticas, a veces ensambladas en cadenas o superpuestas y entrelazadas ${ }^{4}$, como ilustran los siguientes fragmentos estróficos:

En el recuerdo y en el pensamiento

cumpliendo voy mi vida y tu memoria

¡Roca inmortal, límite al mar y al viento[...!] (275)

$\mathrm{Y}$ en este momento despiertan.

En ese momento se alzan,

las medusas de las sirenas,

en el terror petrificadas

$y$ en el zumbido. Se alzan, corren

a los refugios. Gritan, llaman;

apresuradamente extraen del sueño

niños y ropa. Llegan, pasan

atropellándose a lo oscuro.

Se aprietan y rezan. Y aguardan. (319)

\author{
Largamente el atónito soñoliento viajero \\ Regresó, en claras noches \\ de sarcástica luna \\ a una orgía de muebles sucios, deshonorados, \\ entre lentas serpientes \\ de vino y tiempo, orina \\ y tiempo, largamente, \\ mil veces ay; del cementerio en llamas, \\ del terraplén sangriento donde cuece la vida; \\ del foso donde jóvenes \\ cuerpos ya machacados \\ deslíen alma y huesos \\ en ceniza, en veneno: alucinante \\ mundo prostibulario de fetos solemnísimos \\ $y$ ateridos castrados \\ gesticulantemente obscenos. \\ $(345)$
}

${ }^{4}$ Frente a la sucesión de series paralelas de estructuras binómicas en los tres primeros fragmentos, en el último texto de los que se citan a continuación, la pareja ira y coraje es parte del sintagma verbal que contiene otra de las parejas, el tiempo presente: [(amar sufriendo) [el tiempo pasado y [con ira y coraje] el tiempo presente]] En el poema expuesto íntegro en n. 2, este fenómeno de cruce o entrelazado se advierte en otros versos; p. ej., en la tercera estrofa, el conjunto de sintagmas adjetivos coordinados más vivaz y rumorosa forma parte del sintagma nominal cuyo núcleo es agua, que se aparea con el sintagma nominal precedente: [la tierra más ansiada, el agua [más vivaz y rumorosa]]; asimismo, la pareja de adjetivos yuxtapuestos ceñida, enamorada son constituyentes sintácticos modificadores del sustantivo aura, con los que conforma un sintagma nominal que funciona paralelamente, a su vez, a otro sintagma nominal (fuego), ambos constituyentes de sendos sintagmas verbales con verbo copulativo idéntico: [es aura [ceñida, enamorada] y es fuego]. En las estrofas séptima y octava, se produce un ensamble similar: [claman, quieren [vivir, amar]], [me doy todo [con labios y con brazos] y derramo caricias]. Otra suerte de entrelazado es el que representa la correlación (infra), como la que se establece, en el segundo texto citado, entre la pareja de sintagmas preposicionales en la vega, en la cima, y el binomio de sintagmas nominales [ni ternura] vegetal ni frío. 


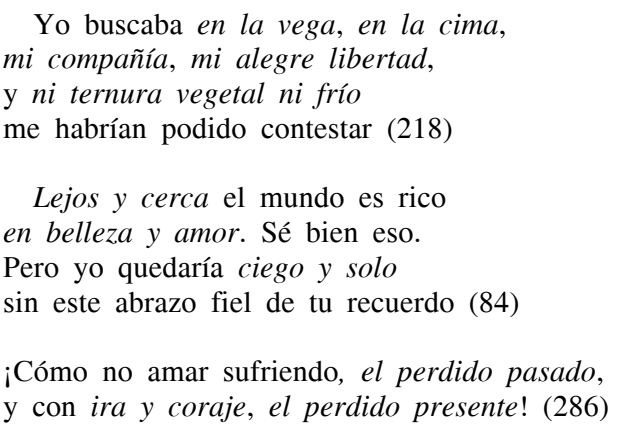

En la poesía de Nora las acciones o procesos verbales se duplican, se aparean dos objetos o realidades o se asocian y repiten los atributos a ellas asignados; en pocas ocasiones, los hechos son simples, y simples e individuales los objetos y sus características o propiedades:

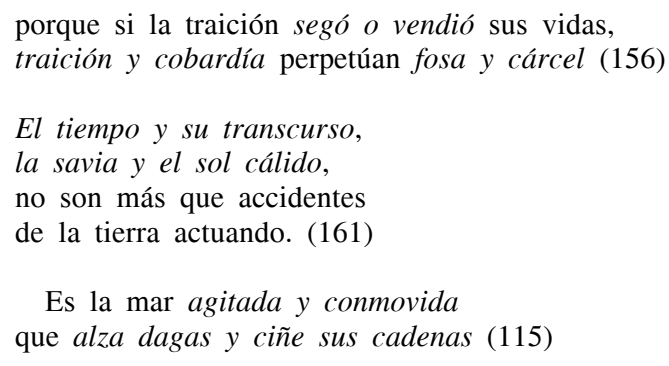

Si cabe interpretar el binomio como expresión de equilibrio, de medida, de orden, de armonía, la proliferación de binomios o parejas en la obra poética de Nora podría responder al empeño del escritor por configurar, en su vertiente formal, una poesía — si, en algún punto, emocionalmente apasionada o tormentosa: por el presente y el futuro de España, por su sentimiento íntimo, etc. - netamente serena, organizada, equilibrada, comedida, sin excesos, sin alardes retóricos, sin turbulencias o estridencias verbales.

2. La manifestación formal más frecuente de la estructura binaria es, como se habrá podido advertir, la construcción compuesta por dos miembros coordinados mediante la conjunción copulativa y ( $n i$ en el caso de estructuras coordinadas negativas) ${ }^{5}$, adoptando así la forma más habitual del

\footnotetext{
${ }^{5}$ Este nexo coordinante viene exigido muchas veces por razones puramente semánticas, como la presencia de la preposición entre, que, entre otras posibilidades (p. ej., sustantivo plural o colectivo), solicita, al menos, dos elementos gramaticalmente asociados o «simétricos», o de ciertos vocablos que denotan 'reciprocidad, simetría', como el adjetivo participial entrelazadas:
} 
binomio en todas las épocas literarias; pero no son en absoluto infrecuentes las parejas acopladas sintácticamente por yuxtaposición o en relación asindética y las coordinadas con la conjunción coordinante disyuntiva $o$, en numerosas ocasiones uniendo antónimos o contrarios (como en los tres últimos textos de la siguiente serie):

Por eso el jardín se llena de gritos multicolores que saben a zumo y menta (72)

Sólo sin mi corazón que es todo cántico y alas (75)

Yo soy un hombre, y canto con los ojos abiertos. Digo cosas que veo, no los ángeles puros ni su oscuro mensaje (153)

No es huracán ni lava (142)

La guerra, la paz sorda impiden, sajan la verdad primera de las palabras. Ah, sólo palabras.

Como flores ahogadas en un charco de lodo.

¡España! ¿Quién podría confundir el océano con una postal verde; un reloj con la lluvia en los cristales? (283)

Miré las rosas de la tierra, erguidas porque las quieran, las besen (67)

\section{¡Adiós!}

Me voy a vivir

la vida dulce o amarga

que me espera. Quedaré (63)

y la voz armoniosa de esa niña que canta cerca o lejos...

¡Dolor! (72)

entre el cardo y la malva, las espigas aún dicen su verdad laboriosa con la espada en la mano (162)

Recuerdo ahora cuánto y cómo, frente al azul del Guadarrama, entre las ruinas de la guerra y los brotes primaverales, hablamos, o miramos mudos (194) tu águila y tu serpiente entrelazadas (154) 


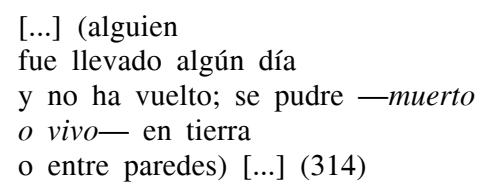

En un elevado número de casos, las estructuras sintácticas coordinadas (o yuxtapuestas) constituyen series rigurosamente simétricas, miembros exactamente homólogos, compuestos por sintagmas que reproducen el mismo esquema constructivo y por unidades léxicas isocategoriales ${ }^{6}$, subrayando así la impronta de una poesía formalmente calculada, enteramente planificada, diseñada por el canon de orden y equilibrio:

\footnotetext{
${ }^{6}$ No sólo se persigue la identidad o equivalencia categorial, e incluso funcional y distributiva (o de ordenamiento), sino que, con extrema frecuencia, se iteran los elementos subordinantes del régimen prepositivo y otras unidades gramaticales, como los determinantes, conformando así esquemas o moldes sintácticos con huecos léxicos de configuración libre o en relación paradigmática: $\mathrm{N}$ \{hierba / piedra\}de mi $\mathrm{N}$ \{pelo / cabeza\} [187], de $\mathrm{N}$ \{decoro / sonrisa\} en los $\mathrm{N}$ \{mayores / niños\} [69], más A \{fuerte / honda\} que el $\mathrm{N}$ \{destino / terror\} (es) el/la $\mathrm{N}$ \{amor / esperanza\} [210], N \{alma / pasión / tristeza $\}$ en el $\mathrm{N}+\mathrm{A}$ \{iris amanecido / granate ardiente / azul (tan) límpido $\}$ [185], un $\mathrm{N}\{$ río / árbol $\}$ que $\mathrm{V}\{$ se incorpora / va a hablar $\}$ [286].

Pero no siempre la ecuación es perfecta o exacta. Puede haber un paralelismo heterocategorial (como en los siguientes cuatro primeros textos, cuyos miembros coordinados presentan la estructura «A $\mathrm{A}+\mathrm{y}$ - [loc. adv. en 328]») o conformarse un miembro desigualmente en constituyentes sintácticos (como en los dos últimos textos en los que o bien uno de los sintagmas nominales aparece expandido con un adjetivo epíteto: alegre, vegetal [218], adormecida [237], o bien el sustantivo término de preposición lleva una relativa especificativa: que la soñó [237]),
}

a esta cárcel maldita y sin guardia (146)

Hemos llegado ya a la cima, descoloridos y sin ansia (141)

Tú ves en aquel cielo, feliz y sin retorno (137)

Estoy solo y a oscuras (328)

Yo buscaba en la vega, en la cima, mi compañía, mi alegre libertad, y ni ternura vegetal ni frío me habrían podido contestar (218)

(Tibio es el cuerpo, interior, solo como un astro en la oscuridad; como una rosa adormecida en el alma que la soñó) (237) 
Todo era vivo, y la humedad ponía hierba en mi pelo, piedra en mi cabeza (187)

El domingo se ha vestido de decoro en los mayores $y$ de sonrisa en los niños (69)

Más fuerte que el destino es el amor; más honda que el terror, la esperanza (210)

Quizá ellos no presientan alma en el iris amanecido; pasión en el granate ardiente, tristeza en el azul tan límpido (185)

Un río que se incorpora, un árbol que va a hablar (286)

Los constituyentes internos de los segundos miembros coordinados o yuxtapuestos no siempre reproducen íntegramente la posición sintáctica que adoptan en el primer miembro (como en los textos precedentes), sino que, aun respetando la equivalencia categorial y funcional, alteran - generalmente, invierten - la distribución. Es así justamente como se concibe como una variante particular del paralelismo la estructuración que dispone los constituyentes sintácticos de uno de los sintagmas equivalentes de forma invertida, cruzada o quiásmica a la que presenta el otro:

Son viejos, lamentables conocidos de cara neutra y de feroces dientes (290)

¡son flores los cristales,

y el aire, dentro, es oro! (99)

y así un pájaro canta y enmudece la lira (117)

si el sol es alto, y largo

el camino, y un hombre

sigue andando su vida (122)

¡Dancen, pues, las caderas jóvenes,

y las bocas de amor se trencen [!] (175)

La formación de versos bimembres, herméticamente cerrados, perfectamente simétricos, con cesura medial exacta $-\mathrm{o}$, en su lugar, el coordinador (como en el primer ejemplo de las dos series de textos previamente citados y los cinco primeros que se citan a continuación)_, o la estructuración de series paralelísticas homólogas dispuestas en versos autónomos, acabados, sin continuidad encabalgante (como en el segundo ejemplo de las antedichas series de textos o los tres últimos de la siguiente), representan eficientísimos 
artilugios formales para provocar esa impresión estética de armonía y equilibrio, máxime cuando las parejas o series plurimembres se escancian en lugares estratégicos o métricamente relevantes, como los finales estróficos o poemáticos ${ }^{7}$ (como el último ejemplo citado en la serie precedente, situado en el cierre total del texto):

verde Aar, claro Bernesga (256)

(;Madrugada de estrellas! ¡Ramo de horas!

Salta un pájaro y vuelan astros y gotas) (226)

¡Oh luna roja! ;Oh noche seca! (103)

Recordaré primero

lo que mis ojos vieron en la aurora;

un cielo azul y un río profundo

subiendo arriba, abajo, como horas (277)

Con los muertos gloriosos estaremos un día fermentando la tierra y bebiendo la nieve (286)

$¡ Y$ huyes! Si el sol, indefinidamente, sueña tu plenitud y hurta el presente (176)

Otra primavera alza

Sobre la tierra otras flores.

¿Quién las vio; quién las alcanza? (176)

¡Pero ve, como entonces,

una escala incansable!:

de la tierra hasta el musgo,

de las ramas al pájaro,

toda nieve a su valle,

toda risa a su boca... (195)

en el hondo color verde

luego gris que ya se pierde

de los céspedes tupidos,

de los árboles mecidos (90)

Hay que detener a la muerte.

Hay que acallar esa amenaza (322)

\footnotetext{
${ }^{7}$ Deben considerarse no sólo las equivalencias formales del nivel sintáctico, sino también del nivel fónico (cf. con el concepto de «matriz convencional» de LEVIN 1962b). En no pocas ocasiones, los miembros apareados son, además, rítmica o métricamente homogéneos; y la perfecta esticomitia señalada por la pausa de fin de verso en las series paralelas o la cesura medial (o, en su lugar, el nexo coordinante) en los versos bimembres simétricos subraya la igualdad formal; v. gr.: oh lúna rója // oh nóche séca (103), [fer]mentándo la tiérra // bebiéndo la niéve (286) [con aféresis de la primera sílaba métrica], tóda niéve a su válle // tóda rísa a su bóca (195), de los céspedes tupídos // de los árboles mecídos (90), etc.
} 
Como ilustra el primer ejemplo de la serie precedente, una de las estructuraciones binómicas con miembros homólogos más representativas en la obra poética de Nora es la que adopta el modelo constructivo de un sintagma nominal simple del tipo $\ll \mathrm{N}+\mathrm{A} » \mathrm{o}\langle\mathrm{A}+\mathrm{N} »$ :

¡león crinado!, jnoche centelleante! (126)

Fuego hermoso y aroma infinito (210)

abierta rosa, frágil hierba (266)

Cuando los conjuntos paralelísticos o miembros equivalentes repiten algún componente léxico, la identidad estructural queda seriamente reforzada:

está en tu carne, está en tu alma (322)

de carne viva, de hombres vivos (274)

la muerte sola, el recuerdo solo (132)

El sentimiento de cierre hermético o de verso - o conjunto versal- clausurado es mayor ${ }^{8}$ cuando las unidades léxicas repetidas adoptan la estructuración invertida o conduplicación quiásmica (epanadiplosis, redditio ${ }^{9}$ ), resultando así formaciones especulares como las siguientes:

\footnotetext{
${ }^{8}$ Adviértase que este efecto de cerramiento no se logra cuando los sintagmas equifuncionales, con repetición léxica o sin ella, no cubren el verso entero; esto es, son sólo parte del mismo:

y aún más las flores, sólo color, promesa sólo, maravillosas prendas de la tierra hecha espíritu (133)

que alza dagas y ciñe sus cadenas

$(115)$

El efecto de cierre también queda levemente atenuado, incluso difuminado, cuando la simetría no es perfecta, normalmente a causa de la interpolación de componentes léxicos o gramaticales externos o no atinentes a la estructuración dual o binaria o a la mera expansión sintáctica de los sintagmas:

se sucede la vida, y al igual, tiempo a tiempo,

la historia se sucede (164)

Decimos NO con ira. Y con sed de justicia lo decimos (324)

Sobre la estructura especular, el primer estudio monográfico en España se debe, hasta donde me alcanza, a Mayoral (1989), reelaborado posteriormente en Mayoral (2002, cap. 5). Sobre este fenómeno, véanse, asimismo, Mayoral (1994, 170-171) y García-Page (1992b, pp. 341-343, 1993, 1994a, pp. 205-214, 1995, 115-116).

${ }^{9}$ La figura ha recibido distintas denominaciones, a veces no coincidentes entre los autores. Véanse, entre otros, LÁZARO CARRETER (1953 [1971]); LAUSBERG (1960, §§ pp. 625-627); FRÉDÉRIC (1985, 51-52); BERISTÁIN (1985); MARCOS (1989); GARCÍA-PAGE (1992a); MAYORAL $(1994,115) \ldots$
} 
Piedras, desnudas, amorosas piedras (101)

¡Sí, quiero alcanzarte,

y tenerte, sí [!] (69)

Otra prueba contundente del carácter elaborado, planificado, de la poesía de Nora es la formación de series correlativas dispuestas en parejas. Desde el punto de vista formal, se trata, como es sabido, de una suerte de paralelismo que conjuga la disposición horizontal y la vertical de los segmentos equivalentes implicados, conocido tradicionalmente en los estudios literarios y de retórica hispánicos como correlación o versos correlativos ${ }^{10}$ (asimismo, gr. sínquisis, lat. mixtura verborum, o versus rapportati, acuñado este último por Curtius 1948: 403-404); desde el punto de vista semántico, consiste en una co-relación de piezas léxicas basada en la repetición parcial o total de unidades isotópicas (en el último caso, sobre todo cuando existe en el término poemático o estrófico «recolección» de los elementos iterativos previamente diseminados $)^{11}$ :

Y la semilla a la tierra fecunda

y el plomo al corazón estéril,

para que bala y rosa también tengan su sitio (165)

¡Oh mediodía! Mis oscuros ojos

del valle al monte lentamente van,

buscando entre lo verde, $o$ en lo blanco,

ay, rama o nieve en la que descansar

$[\ldots]$

Yo buscaba en la vega, la cima,

mi compañía, mi alegre libertad,

y ni ternura vegetal ni frío

me habrían podido contestar (218)

Como se ha podido observar en algunos ejemplos citados hasta el momento, las unidades léxicas emparejadas con bastante frecuencia guardan entre sí algún tipo de vínculo semántico, como la sinonimia o parasinonimia y, sobre todo, la antonimia:

La lenta oscuridad se quiebra,

se triza en sus vértices últimos (190)

${ }^{10}$ La bibliografía sobre la correlación es abundante. Los primeros trabajos de notable relevancia en España se deben a Dámaso Alonso y, poco después, Carlos Bousoño. Véanse, especialmente, AlONSO $(1955,222-247$ y 1988, 116-128) y ALONSO Y BOUSOÑo (1951, passim); asimismo, Alonso (1944, 1959, 1966-67, 1971); CAMPO (1946) y BALCELLS (1975), entre otros. Nosotros hemos dedicado unas páginas a la correlación en Cervantes (GARCÍA-PAGE 1992b, pp. 344-345 y 1995, pp. 118-121).

${ }^{11}$ La correlación semántica que se establece entre los signos tipográficamente destacados de las ilustraciones sería la siguiente: semilla : rosa / plomo : bala (165); lo verde : rama : la vega : vegetal // lo blanco : nieve : la cima : frío. 
Tú, como un niño con un juguete tuyo, ;rómpeme, destrózame! Ven, mira (230)

Ahora pienso en tu voz, y en tu silencio, y en nuestra comunión ardiente y viva a través de las cosas (194)

a la pura belleza terrestre. Toda belleza es rival, enemiga del verdadero amor, ay, tan lejano a la delicia (267)

Roja como la vida es tu crin en el viento que acaricia y desgarra, tal una viril mano que ciñera la espalda de esta Tierra entregada; radiante y llameante cual la vida más bella (118)

el tiempo de luz y de sombra (217)

Lejos y cerca el mundo es rico en belleza y amor. Sé bien eso (84)

más dentro del amor que odia y que ama (142)

un bautismo de muertos que la hayan adorado o maldecido, que hayan en ella descansado (278)

Quiero poner un poco de luz en este acto de esclavitud y de mordaza puesta sobre sangre reseca o renovada (155)

La simetría bilateral del verso bimembre y el paralelismo representan precisamente una clase especial de mecanismos de realce de los elementos antagónicos, de los sinónimos o de los signos de un mismo campo semántico:

¡Amor de siempre; amor de nunca, si existe el tiempo sin el llanto, oye esta voz de arena y sombra! (85)

Sabedlo ahora vosotros, que por la libertad ofrecisteis la vida, aceptasteis la muerte (155)

...Y, entonces,

aunque el muro no oiga, aunque el suelo no oiga, aunque el cielo no oiga, los queremos también, temblamos (229)

Pero la asociación de voces semánticamente semejantes o de contrarios no es algo gratuito, un artilugio meramente efectista, sino que está al servi- 
cio de la expresión de sentimientos. La ditología sinonímica no suele resultar un mecanismo retórico vacuo o mero ripio, como operaba muy habitualmente en la literatura española áurea (Cervantes, por ejemplo ${ }^{12}$ ), sino que busca normalmente la precisión, el matiz, la diversidad. Por su parte, la antítesis obedece a las fuerzas antagónicas que a menudo transitan el pensamiento y el sentir del poeta: por un lado, la realidad española cruel, salvaje, destructora, la España triunfalista, altiva y despiadada de los vencedores, y, por otro, el pueblo oprimido y subyugado, la España rota, destruida, desencantada, de los vencidos, la búsqueda de la libertad y la apertura; por un lado, la desolación y la muerte, el atraso y el ostracismo, y, por otro, la añoranza de paz y reconciliación, el deseo de recuperación y progreso, el ansia de alegría y de vivir...

Aunque Eugenio de Nora persigue una poesía sobria, alejada del artificio retórico, reñida con el malabarismo verbal, en algunas ocasiones se deja tentar por el juego con el significante y sus poemas rezuman esporádicamente parejas de términos parónimos, rimantes o aliterados ${ }^{13}$ :

${ }^{12}$ La bibliografía general sobre la ditología o binomio sinonímico es abundante, aunque escasean los estudios en español. Véase a modo de ejemplo GARCía-PAGE (1998) sobre dicho recurso retórico en la poesía de Cervantes; en dicho estudio se recogen algunos de los principales trabajos monográficos sobre tal figura.

${ }^{13}$ Es evidente que hay voluntad de juego, de manipulación del material lingüístico. La mera utilización de la estructura geminada o el paralelismo es una prueba; la selección de los vocablos es, sin ningún género de dudas, otro argumento de tal planificación: p. ej., las voces dorada y creadora conforman un sintagma cerrado al distribuir los segmentos repetidos que dan lugar a la paronomasia al principio y al final, respectivamente: DORA[da y crea]DORA. En la obra completa de Eugenio de Nora hay más ilustraciones del fenómeno paronomásico, aunque no siempre se presente bajo una estructura binaria; también están presentes otros artificios lúdicos de base fonética (fónico-semántica, fónico-morfológica...), como el calambur, el eco, la parequesis o la similicadencia (homeotéleuton), como ilustran los siguientes textos:

la virtud muerta... el corazón resiste

apenas, ay, ¡a penas!, la embestida (293) $[\mathrm{A}(a)+\mathrm{B}$ (penas) $=\mathrm{AB}$ (apenas)

Yo paso entre los mares; oigo las alas $[\mathrm{A}($ a $)+\mathrm{B}($ las $)=\mathrm{AB}$ (alas)

a las claras palomas del amor... [...] (212) [cf. anagrama imperfecto AMOr : palOMAs + similicadencia -as

No huir, ¡ir hacia dentro! Hemos vuelto a la vida (263)

(Bota y rebota

la luna lunera

por la carretera.) (76)

que soy la ola que alcanza el sol ahora (145) [cf., además, la serie ola - alcanza el - sol

en olivos, naranjas, monjas, cobre (336) 
El inventario de artificios lúdicos de orden esencialmente fónico quedaría incompleto si no se tuvieran en cuenta otros mecanismos de juego verbal como el encabalgamiento «semántico» del tipo:

Y aún otra vez cantar cómo te amo, patria injuriada por tus mismos hijos de perra, los que ensucian (155)

desde Euzkadi de hierro a Extremadura, en pie de hambre, a Andalucía clara como nunca (316)

Y el sol da el arco iris de tu cuerpo de flor de verano (86)

Para ti sola, por la madrugada de luz antigua que en tus ojos hay (254)

Sobre estos fenómenos de retórica y juegos de palabras, véase especialmente, entre otros, GARCía-PAGE (1990, 1991a, 1992c, 2003, passim, 2005) y la bibliografía en ellos citada. Asimismo, MARTínez GARCía (1975 y 1976) y Serra (2000).

La voluntad de juego con el lenguaje queda también patente en los niveles léxico y sintáctico, sin caer en la extravagancia o cursilería. Eugenio de Nora regala al lector para su deleite un puñado de creaciones léxicas novedosas (a) y de estructuras gramaticalmente anómalas (como ciertos usos especiales del verbo, cual la transitivización de verbos intransitivos o inacusativos [los siete primeros textos]; la composición de sintagmas nominales definidos con artículo como complementos directos de haber [los dos textos siguientes]; la coordinación irregular de adjetivos de distinta clase sintáctica [los dos últimos textos]; la selección anómala de la clase de sustantivo objeto directo de hacer: un acotador no temporal [262], o del régimen prepositivo: un adverbio [75]) (b):

(a) En esta noche intransitada (189)

ojos como ventanas

abiertas en la noche sucia y desestrellada (345)

Música frágil, tierna ola esquerzada del verde valle (344)

nos azuzó en sus fiestas de púrpura hederosa (345)

verás de pronto, cieleado, inmenso, un mundo sólo florido hacia ti (254)

(Sería tan bello abandonarse, primaverear de almendro el humo, y recordar aquellos días igual que flores rociadas...) (262)

la tierra ocre y entreparda (273)

O hay el que aprieta sombra de noches deslunadas (284) 
y muerte, y sobremuerte, y tantos mares (298)

y las abuelas. Sí; pensadlas...

Y despensad, que ya no existen (320)

(b) Verla, nacerla, mirarla (75)

me naciste un día (68)

iflorécete y huye [i] (68)

Ilusión, tú embriagas la boca,

la floreces en pétalos vivos!... (211)

Felicidad contigo. Nos viven y sustentan

en lo hondo de la noche las veraces estrellas (236)

Tengo también esa condición dura

de vivirte, hombre tuyo, sin queja y con desprecio (288)

[...] Nadie

vuelve atrás, si no muere

y en estatua de sed se sobrevive.) (265)

aún hay la gana dura (289)

Acaso está lloviendo, acaso hubo

la naranja que no alcanzó su mano (291)

Vivo, pensándote. Es de noche,

y fuera hace luna y frío (262)

¡Hoy, mañana! Vive en siempre

el alma cuando así ama (75)

[...] ¿A las miradas

de qué gacela fugitiva y mía?

Me aparecen siempre

con uniformes vestidos por dentro,

universales, repetidos, unos (290)

La clase de coordinaciones irregulares de los dos últimos ejemplos no tienen que ver con otra suerte de relación coordinativa basada en la ruptura de isotopías —el cual constituye otro artificio poético profusamente empleado en la literatura contemporánea (véase especialmente García-Page 1994b)—, del tipo:

Las cosas, y la vida misma, No son nadie; ver nubes y horas que se deshacen sin sentido (88)

$\mathrm{y}$ andamos, firmes, una ruta de sed y zarzas abrasadas (200) 


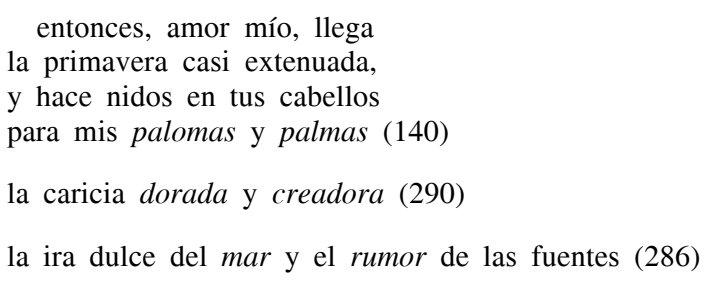

Los mismos artilugios sintácticos que servían para subrayar la antítesis son igualmente eficaces para destacar los juegos fónicos:

pájaros de hambre para volar lejos,

$\sin f e, \sin f i n$, sobre nieve (175)

Como las alas también vuelven, como las olas y su flor (247)

También puede considerarse como una manifestación particular de la estructuración binaria o bimembración, además de constituir una prueba más del artificio poético, la repetición o reduplicación léxica o sintagmática, exacta o parcial (geminatio, conduplicatio, epizeuxis), combinada frecuentemente con alguna otra suerte de estructura binaria, como en el fragmento arriba citado ¡Amor de siempre; amor de nunca[!]), o algún mecanismo sintáctico, como, por ejemplo, la simetría. En algunas ocasiones (como los dos primeros textos que se proponen a continuación), de tal mecanismo resulta un verso bimembre, simétrico y cerrado:

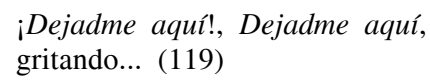

Bien sé que hay muchos, soñadores (como yo rodeados de desgracia y caminos) (299)

Sobre el primer tipo de fenómenos descrito, la creatividad léxica en el lenguaje literario, hay bibliografía abundante; si bien destacamos los estudios de Mayoral (1982, 1983 y 1985) y García-Page (1988, cap. 3, 1991b, 1992d, 1996 y 2007a y 2007b); sobre el segundo, la anomalía sintáctica, escasean los trabajos monográficos, si bien existen observaciones dispersas en trabajos de conjunto. Véase especialmente García-Page (2004).

Existen otras muestras de la artificiosidad y virtuosismo formal de la lírica de E. de Nora, como el hipérbaton, a veces tan violento como el paréntesis del primer texto que se aduce a continuación:

Llegando al fin, recordaréis como un paisaje, de este libro (266)

Y a decir voy tu nombre de rocío (81) 
vivir un destino

vivir y vivir (69)

Tiempo y tiempo pasó. ¡Qué hermosos labios tiene la vida, qué candentes pechos para fundir amando cuanto roza! (261)

y el mismo sol, el mismo sol de oro va decayendo con dulzura astral (219)

Miraba antes las rosas. Quería tener, tenerlas. Quería querer. Quería. Mas la forma no sueña (236)

te las ofrezco hoy como un ramo

de rosas, sí, como un ramo de frescas rosas. Junto a ellas suelo pensarte [...] (263)

\section{REFERENCIAS BIBLIOGRÁFICAS}

Alonso, D., La lengua poética de Góngora [1927], Madrid, CSIC, 1961. Anejo XX, de RFE.

—, «Versos plurimembres y poemas correlativos», RBAM, 13, 1944, pp. 89-191.

- Poesía española, Madrid, Gredos, 1950.

—, Estudios y ensayos gongorinos, Madrid, Gredos, 1955.

—, «La poesia del Petrarca e il petrarchismo», Lettere italiane, 11, 1959, pp. 277-319.

—, «Primer escalón en los manierismos del siglo XVI. Plurimembraciones y correlaciones en Gutierre de Cetina», Asclepio, 18-19, 1966-67, pp. 61-76.

—, (1971). Pluralità e correlazione in poesia, Roma, Ediciones Adriatica.

—, Francisco de Medrano. Poesía, Madrid, Cátedra, 1988 [orig. Vida y obra de Medrano, Madrid, CSIC, 1948].

Bousoño, C., Seis calas en la expresión literaria española, Madrid, Gredos, 1951.

BALCELls, J.M., «Estructuras correlativas de Miguel Hernández», Miguel Hernández, IFACH, M. de G. (ed.), Madrid, Taurus, 1975, pp. 46-54.

Beristáin, H., Diccionario de retórica y poética, México, Porrúa, 1985.

CAMPO, A. del, «Plurimembración y correlación en Francisco de la Torre», RFE, 30, 1946, pp. 385-392.

CURTIUS, E. R., Literatura española y Edad Media latina [1948], México, FCE, 1981.

FRÉDÉRIC, M., La répétition. Étude linguistique et rhétorique, Tubinga, Max Niemeyer Verlag, 1985.

García-Page, M., La lengua poética de Gloria Fuertes, Madrid, Univ. Complutense, 1988.

—, «Algunas observaciones acerca del calambur», Investigaciones Semióticas III, J.ROMERA y A. Yllera (ed.), Madrid, UNED, 1990, vol. 1, pp. 431-448.

—, «En torno al 'encabalgamiento'. Pausa virtual y duplicidad de lecturas», RLit, 53/106, 1991a, pp. 595-618.

-, «El adverbio en -mente. Motivación contextual en formaciones léxicas anómalas», $A E F$, 14, 1991b, pp. 149-181.

—, «Precisiones terminológicas en Retórica (I): figuras de repetición lingüística», $N E F, 7$, 1992a, pp. 431-448. 
-, «Estructuras de 'sintaxis inversa' en Cervantes», Estudios filológicos en homenaje a Eugenio de Bustos Tovar, BARTOL, J. A. y otros (eds.), Salamanca, Univ. de Salamanca, 1992b, vol. 1, pp. 327-347.

—, «Datos para una tipología de la paronomasia», Epos. Revista de Filología, 8, 1992c, pp. $155-243$.

—, «Barbarismos. Algunos ejemplos de creaciones léxicas insólitas», BRAE, 72, 1992d, pp. 349-374.

—, «En torno a la sintaxis gongorina de Miguel Hernández», RCEH, 17/3, 1993, pp. 419-435.

—, «Notas a La lengua poética de Góngora, de Dámaso Alonso» AEF, 17, 1994a, pp. 201-222.

—, «La coordinación lingüística como sistema de ruptura de isotopías», Semiótica(s). Homenaje a Greimas, J. RomerA, y otros (eds.), Madrid, Visor, 1994b, pp. 203-218.

—, «El cultismo sintáctico en Cervantes». Annali dell'Istituto Universitario Orientale, 37/2, 1995, pp. 97-122.

-, «Formaciones denominales en -mente en el discurso poético», En torno al adverbio español y los circunstantes,. G. WOTJAK (ed.), Tubinga, Gunter Narr Verlag, 1996, pp. 161-170.

—, «La ditología sinonímica en Cervantes», Retórica y Texto, A. RuIz Castellanos, y otros (eds.), Cádiz, Univ. de Cádiz, 1998, pp. 260-266.

—, El juego de palabras en la poesía de Gloria Fuertes, Madrid, UNED, 2003.

—, «Estructuras desviantes y discurso poético», Homenaje al profesor Estanislao Ramón Trives, R. Almela, y otros (eds.), Murcia, Univ. de Murcia, 2004, vol. 1, pp. 311336.

—, "Juegos idiomáticos en la poesía contemporánea", El lenguaje de la literatura (siglos XIX y XX), R. Senabre, y otros (eds.), Salamanca, Ambos Mundos, 2005, pp. 113176.

—, «Formas de creatividad léxica en la poesía contemporánea. El ejemplo de Gloria Fuertes», Morfología. Investigación, docencia, aplicaciones, J. C. Martín camacho y M. I. Rodríguez Ponce (eds.), Cáceres, Universidad de Extremadura, 2007, pp. 79-94.

—, «Notas sobre la creatividad léxica: acrónimos, seudoacrónimos y otras extravagancias léxicas en la poesía de Gloria Fuertes», Homenaje a César Hernández, 2007b, e. p.

GARCía MÉNDEZ, M.J., Eugenio de Nora: Una aproximación a su poesía, Valladolid, Junta de Comunidades de Castilla y León, 2003 (orig. Aproximación a la obra poética de Eugenio de Nora, Salamanca, Univ. de Salamanca, 1998).

JAKOBSON, R., «Lingüística y poética» [1960], Ensayos de lingüística general, Barcelona, Ariel, 1963, pp. 347-395.

LAusberg, H., Manual de retórica literaria [1960], Madrid, Gredos, 3 vols., 1966-1967.

LÁzaro Carreter, F., Diccionario de términos filológicos [1953], Madrid, Gredos, 1971.

-, «Función poética y verso libre», Homenaje a Francisco Ynduráin, Zaragoza, Univ. Zaragoza, 1972, pp. 201-216 (reimp. en F. LÁZARo CARRETER (ed.), Estudios de poética. (La obra en sí), Madrid, Taurus, 1976, pp. 51-62).

LEVIN, S.R., «Coupling in a Shakespearen sonnet» [1962a], Linguistics and literary Style, D. C. FreEman (ed.), Nueva York, Holt, Rinehart \& Winston, Inc., 1970, pp. 197-205.

—, Estructuras lingüísticas en poesía [1962b], Madrid, Cátedra, 1974.

MARCos, F., Diccionario práctico de recursos expresivos (figuras y tropos), Cáceres, Univ. de Extremadura, 1989.

Martínez, J. A., Propiedades del lenguaje poético, Oviedo, Univ. Oviedo, Publ. de Archivum, 1975.

—, «Repetición de sonidos y poesía», $A O, 26,1976$, pp. 77-102.

MAYORAL, J.A., «Creatividad léxica y lengua literaria: las formaciones adverbiales en -MENTE», Dicenda, 1, 1982, pp. 35-53. 
— «Creatividad léxica y lengua poética», Serta Philologica F. Lázaro Carreter, Madrid, Cátedra, 1983, vol. 1, pp. 379-390.

-, «Creatividad léxica y lengua poética: algunos ejemplos de motivación contextual en formaciones léxicas prefijadas», Philologica Hispaniensia. In Honorem Manuel Alvar, Madrid, Gredos, 1985, vol. 2, pp. 435-446.

—, «Sobre 'estructuras especulares' en el discurso en verso», Philologica. Homenaje a D. Antonio Llorente, Salamanca, Univ. de Salamanca, 1989, vol. 2, pp. 195-209.

—, Figuras retóricas, Madrid, Síntesis, 1994.

-, Estructuras retóricas en el discurso poético de los siglos XVI y XVII, Valencia, Tirant lo Blanch, 2002.

Ruwet, N., Langage, musique, poésie, París, Senil, 1972.

—, «Parallélismes et déviations en poésie» [1974], Langage, discourse, societé. Pour Émile Benveniste, N. Ruwet y otros (eds.), París, Seuil, 1975, pp. 307-351.

SERRA, M., Verbalia. Juegos de palabras y esfuerzos del ingenio literario [2000], Barcelona, Península, 2001.

Fecha de recepción: 24 de abril de 2007

Fecha de aceptación: 12 de febrero de 2008 